Note

\section{Degradation of Homogentisic Acid by Aspergillus fumigatus ATCC 28282}

\author{
Fumiki Yoshizako, Atsuo Nishimura \\ and Teruo UENO* \\ Department of Applied Biology, \\ Radiation Center of Osaka Prefecture, \\ Shinke-cho, Sakai, Osaka 593, Japan \\ * Department of Agricultural Chemistry, \\ Faculty of Agriculture, University of Tottori, \\ Tottori 680, Japan
}

Received November 8, 1984

Many studies on the formation of homogentisic acid (2,5-DiOHPA) from tyrosine, ${ }^{1 \sim 3)}$ phenylalanine $^{4 \sim 7)}$ and phenylacetic $\operatorname{acid}^{8 \sim 10)}$ by microorganisms have appeared in the literature. Two degradative pathways for 2,5DiOHPA in microorganisms have been described: (i) the gentisic acid pathway ${ }^{11)}$ and (ii) the oxidative ring cleavage pathway. ${ }^{12)}$

However, little information is available on the fungal degradation of 2,5-DiOHPA in contrast to the many investigations with bacteria. Although 2,5-DiOHPA was oxidized directly to ring-cleaved products by $A$. niger during sporulation, ${ }^{6,13)}$ it is not certain whether the same reactions occur when other species of Aspergillus oxidize 2,5-DiOHPA.

In a previous paper, ${ }^{7)}$ we reported the formation of 2,5DiOHPA as a key intermediate in the metabolism of phenylalanine and tyrosine by $A$. fumigatus ATCC 28282 . This note describes the gentisic acid pathway for the degradation of 2,5-DiOHPA by $A$. fumigatus ATCC 28282.

The conidia of $A$. fumigatus ATCC 28282 were inoculated on a medium containing $2.5 \%$ glucose, $2.0 \%$ monosodium glutamate $\cdot \mathrm{H}_{2} \mathrm{O}, 0.5 \% \mathrm{KH}_{2} \mathrm{PO}_{4}$ and $0.2 \%$ $\mathrm{MgSO}_{4} \cdot 7 \mathrm{H}_{2} \mathrm{O}$ in $300-\mathrm{ml}$ Erlenmeyer flasks $(150 \mathrm{ml}$ per flask) for $7 \sim 10$ days at $30^{\circ} \mathrm{C}$ without shaking. The mycelial mats were washed once with sterile distilled water and reincubated at $30^{\circ} \mathrm{C}$ for $3 \sim 5$ days with an aqueous solution of the substrate $(0.01 \% 2,5$-DiOHPA, pH 6.0) dissolved in $0.2 \mathrm{M}$ disodium phosphate- $0.1 \mathrm{M}$ citric acid buffer ( $100 \mathrm{ml}$ per flask). Under these conditions, 2,5DiOHPA was not converted to gentisic acid and gentisaldehyde in control experiments in which mycelial mats were omitted.

For the detection and identification of the intermediary products of 2,5-DiOHPA degradation, the culture medium was acidified to $\mathrm{pH} 4.0$ with $\mathrm{H}_{2} \mathrm{SO}_{4}$ and extracted with ethyl acetate. The ethyl acetate extract was concentrated and subjected to thin-layer chromatography (TLC) on silica gel plates $(200 \mathrm{~nm}, 20 \times 20 \mathrm{~cm}$, without fluorescence, Tokyo Kasei). The plates were developed in 3 solvent systems: A, chloroform-ethyl acetate-formic acid $(50: 10: 2.5, \mathrm{v} / \mathrm{v}) ; \mathrm{B}$, benzene-dioxane-acetic acid $(90: 20: 4, \mathrm{v} / \mathrm{v})$; and $\mathrm{C}$, hexane-ethyl ether $(30: 70, \mathrm{v} / \mathrm{v})$. The metabolites were detected on TLC plates by the fluorescence under ultraviolet light and by spraying FolinCiocalteu reagent $(\mathrm{PR})^{14)}$ (Table I), and identified by mass spectrometric analysis.

The bands of metabolites A and B (Table I) were separately scraped off from the TLC plates and eluted from the silica gel with ethyl ether. Each concentrated ether solution was introduced directly into the ionization chamber $\left(270^{\circ} \mathrm{C}\right)$ of a mass spectrometer (Shimadzu-LKB-9000) at $70 \mathrm{eV}$ energy. The mass spectra of metabolites $\mathrm{A}$ and $\mathrm{B}$ were identical with those of authentic gentisic acid and gentisaldehyde.

These facts were confirmed by the use of radio tracer methodology. Radioactive 2,5-DiOHPA was prepared

Table I. Thin-layer Chromatography of Fungal Degradation Products of HoMOgentisic ACID

\begin{tabular}{|c|c|c|c|c|c|}
\hline \multirow{2}{*}{ Compounds } & \multicolumn{3}{|c|}{$R f$ Values $^{a}$} & \multicolumn{2}{|c|}{ Detection $^{b}$} \\
\hline & Soln. A & Soln. B & Soln. C & $\mathrm{D}_{1}$ & $\mathrm{D}_{2}$ \\
\hline \multicolumn{6}{|l|}{ Authentic } \\
\hline Gentisic acid & 0.50 & 0.52 & 0.08 & Dark blue & Blue fluorescence \\
\hline Gentisaldehyde & 0.67 & 0.78 & 0.64 & Dark blue & Dark yellow \\
\hline \multicolumn{6}{|l|}{ Metabolites } \\
\hline A & 0.50 & 0.52 & 0.08 & Dark Blue & Blue fluorescence \\
\hline B & 0.67 & 0.78 & 0.64 & Dark blue & Dark yellow \\
\hline
\end{tabular}

a Soln. A, chloroform-ethyl acetate-formic acid $=50: 10: 2.5(\mathrm{v} / \mathrm{v})$; Slon. B, benzene-dioxane-acetic acid $=$ $90: 20: 4(\mathrm{v} / \mathrm{v})$; Soln. C, hexane-ethyl ether $=30: 70(\mathrm{v} / \mathrm{v})$.

${ }_{b} \quad \mathrm{D}_{1}$, Folin-Ciocalteu reagent; $\mathrm{D}_{2}$, ultraviolet light. 
microbially from DL- $\left[3-{ }^{14} \mathrm{C}\right]$-tyrosine $\quad(50 \mu \mathrm{Ci}, \quad \mathrm{New}$ England Nuclear) according to Yoshizako et al.,") and the radioactive 2,5-DiOHPA was separated by TLC with solvent A $(R f=0.14)$. The band corresponding to authentic 2,5-DiOHPA was scraped off from the plates and eluted form the silica gel with $20 \mathrm{ml}$ of distilled water. The specific radioactivity of 2,5-DiOHPA $\left(9 \times 10^{7} \mathrm{dpm} / \mathrm{mmol}\right.$ 2,5-DiOHPA) in this solution was the same as that of tyrosine $\left(8.3 \times 10^{7} \mathrm{dpm} / \mathrm{mmol}\right.$ tyrosine $)$. Twenty $\mathrm{ml}$ of the eluate was added to $480 \mathrm{ml}$ of $0.2 \mathrm{M}$ disodium phosphate$0.1 \mathrm{M}$ citric acid buffer containing $0.15 \mathrm{~g}$ of cold 2,5DiOHPA $\left(7.5 \times 10^{5} \mathrm{dpm} / 500 \mathrm{ml}, \mathrm{pH} 6.0\right)$. The mixture was used as a replacement culture medium ( $100 \mathrm{ml}$ per flask). After cultivation $\left(30^{\circ} \mathrm{C}\right.$. 3 days $)$ and treatment of the culture filtrate by the same method as that described in non-radioactive experiments, the concentrated ethyl acetate extract $\left(20 \mu 1,2.3 \times 10^{4} \mathrm{dpm}\right)$ was spotted onto a TLC plate. The TLC plate was developed in solvent B. After detection of the presence of gentisic acid and gentisaldehyde by the fluorescence under ultraviolet light and by spraying with PR, each spot was scraped off from the TLC plate. The radioactivity of each spot was measured with a liquid scintillation counter (TRI CARB 3380). It was found that the radioactivity of ${ }^{14} \mathrm{C}$-labelled 2,5-DiOHPA was incorporated into the transiently accumulated gentisic acid $(290 \mathrm{dpm})$ and gentisaldehyde $(65 \mathrm{dpm})$ per plate.

Gentisic acid was also isolated from the culture fluid in which washed mycelial mats had been incubated at $30^{\circ} \mathrm{C}$ for 3 days with gentisaldehyde $(0.01 \%, \mathrm{pH} 6.0)$ dissolved in $0.2 \mathrm{M}$ disodium phosphate- $0.1 \mathrm{M}$ citric acid buffer ( $100 \mathrm{ml}$ per flask). The melting point, and the ultraviolet, infrared $(\mathrm{KBr})$ and mass spectra of this compound were essentially the same as those of authentic gentisic acid.

The data obtained in this study show that $A$. fumigatus ATCC 28282 clearly degrades 2,5-DiOHPA to gentisic acid via gentisaldehyde.
Acknowledgment. We thank Dr. M. Hamada, Kinki University, and Dr. M. Chubachi, Radiation Center of Osaka Prefecture, for the helpful discussions and mass spectrometric analysis.

\section{REFERENCES}

1) J.D. Jones, B.S.W. Smith and W.C. Evans, Biochem. J., 51, xi (1952).

2) N. Kunita, Med. J. Osaka Univ., 7, 203 (1956).

3) K. Yuasa, K. Ishizuka and T. Sakasai, Agric. Biol. Chem., 42, 167 (1978).

4) S. Dagley, M. E. Fewster and F. C. Happold, J. Gen. Microbiol., 8, 1 (1953).

5) K. Yuasa, K. Ishizuka, S. Kaburaki and T. Sakasai, Agric. Biol. Chem., 39, 2199 (1975).

6) G. Kishore, M. Sugumaran and C.S. Vaidyanathan, J. Bacteriol., 128, 182 (1976).

7) F. Yoshizako, A. Nishimura and T. Ueno, Nippon Nôgeikagaku Kaishi, 56, 1135 (1982).

8) N. Kunita, Med. J. Osaka Univ., 6, 703 (1955).

9) T. Ueno, F. Yoshizako and A. Nishimura, Can. J. Microbiol., 19, 393 (1973).

10) J. J. Anderson and S. Dagley, J. Bacteriol., 141, 534 (1980).

11) Y. Sakamoto, T. Higashi, M. Kanda and Y. Nakata, J. Biochem. (Tokyo), 55, 72 (1964).

12) R. L. Crawford, "Lignin Biodegradation and Transformation," John Wiley and Sons, Inc., New York, 1981, pp. 74 75.

13) M. Sugumaran and C.S. Vaidyanathan, J. Indian Inst. Sci., 60, 125 (1978).

14) O. Folin and V. Ciocalteu, J. Biol. Chem., 73, 627 (1927). 